\title{
Childhood Malignant Mesenchymoma
}

National Cancer Institute

\section{Source}

National Cancer Institute. Childhood Malignant Mesenchymoma. NCI Thesaurus. Code C8097.

A malignant mesenchymoma occurring in children. 